\title{
Objective forensic assessment of competence versus severity of symptoms and assessment of functioning for schizophrenic inpatients based on Egyptian law
}

\begin{abstract}
Since, 1944 the Egyptian legal regulations for the admission of the mentally ill patients had not been changed until recently, at the year 2009. The application of the newly established law, the law of the care of the mentally ill patients which was inspired by a relatively new concept; the competence to consent to treatment was found to lake the knowhow and the practice revealed that, many physicians and psychiatrists answer the question of competence with the insight terms. This work is aiming for better understanding of the law for mentally ill patients through highlighting the concept of the competence and making a roster work for the first time in Egypt as regard the objective assessment of competence to consent to treatment using forensic instruments and clinical scales. Also, demonstrating by the results of the work, how objective assessment not only evaluates but also enhances the decision making capacity.
\end{abstract}

Volume I Issue I - 2015

\author{
Amr M Elghazali,' Ahmed Dobie, ${ }^{2}$ Maged \\ Abdel Kader ${ }^{2}$ \\ 'Forensic Pathologist, Egypt \\ ${ }^{2}$ Psychiatrist, Egypt
}

Correspondence: Amr M Elghazali, Forensic Pathologist, 5301 almahata, Hail, Saudi Arabia, Egypt, Po Box: 6061, Zip code: 8|442, Tel +96654342 |400, Email ghazali_dr_amr@hotmail.com

Received: June II, 20I5 | Published: July 06, 2015

Keywords: competence, law, schizophrenia, assessment

\section{Abbreviations}

BPRS, Brief Psychiatric Rating Scale; GAF, Global Assessment of Functioning Scale; NCMH, National/local Council of Mental Health; TRAT, Thinking Rational about Treatment

\section{Introduction}

In medical ethics, the principle of a patient's self-determination obliges the physician to obtain the patient's consent prior to medical treatment. ${ }^{1}$ Law provides for the protection of individuals from medical or psychological interventions against their desires, except in certain emergency or court-ordered circumstances. ${ }^{2}$ The declaration of Madrid stresses the patient's rights to be fully informed of the nature of the condition of the proposed diagnostic and therapeutic procedures including possible alternatives and the right to choose between available methods. ${ }^{3}$ A condition for valid informed consent is the patient's competence, which may be impaired, particularly in patients with mental problems. ${ }^{4}$ The term competence to consent refers to an individual's legal capacity to accept a proposed treatment, to refuse treatment, or to select among treatment options. ${ }^{2}$ The question of an individual's competence to consent to or refuse a proposed treatment intervention requires that the individual must

I. Be provided information relevant for the decision.

II. Make the choice voluntarily.

III. Be competent to decide. ${ }^{2}$

In most cases, if the situation causes the physician to examine competence, he will proceed using his own subjective judgment and clinical experience and has difficulty applying standards suggested in the literature [5]. Physicians also often evaluate competence differently. ${ }^{6}$ The 'MacArthur Treatment Competence Study 'MacCAT-T, using instruments relating to the following four legal standards.

I. To understand information relevant to the decision.

II. To manipulate the information rationally.

III. To appreciate the significance of the information disclosed about the illness and possible treatments.

IV. To express a choice. ${ }^{7}$

Legal standards for competence to consent to or refuse treatment do not specifically require that deficits in relevant functional abilities must be a "product" of mental illness. ${ }^{2}$ Schizophrenia is associated with poor insight and cognitive dysfunction, which may influence decisional capacity, yet the presence of schizophrenia, does not mean the patient has impairment in capacity. ${ }^{8}$ We are aiming to identify the four types of cognitive abilities, which are the domain of functional abilities related to legal definitions of competence to make treatment decisions. For complying with the relatively new legislation in Egypt that consider the presence of severity of symptoms and deterioration of functions for the involuntary admission, the Brief psychiatric rating scale (BPRS), ${ }^{9}$ and the Global assessment of functioning scale (GAF) are applied. ${ }^{10}$

\section{Egyptian laws}

\section{The Code No. I4I/1944}

The Law of the Detention of the Psychotic Patients;

I. The detention was in cases of threatening of public security.

II. Upon request of relatives and authorized by a general physician. 
III. The period of detention is 1 year then extended, the same way, into 2, 3, 5, then another 5 years (Egyptian Official Newspaper, 1944).

IV. Opened gate for the political and social abuses.

V. Observation council including Medico-Legal Physician.

\section{The Code No.7 I/2009}

The Law of the Care of the Mentally Ill Patient;

I. This law defined the rights of those patients in care and therapy.

II. The admission for treatment should be authorized by a psychiatrist with an audience from the National / local Council of Mental Health within one week.

III. Egyptian National Council of Mental Health and Independent reevaluation is also defined.

IV. Voluntary admission: should depend on patient's competence and free Volition to give informed written consent. The patient has the right to ask for being discharged.

V. The voluntary admission (term 10): depending on acceptance. Supported with subjective evaluation by the psychiatrist that he is competent.

VI. Involuntary admission: conditioned with

i. Presence of apparent signs and symptoms of severe mental illness.

ii. Either, serious risky symptoms impacting the safety, health or life of the patient or the others or possibility of impending sever deterioration of the mental status.

\section{Procedures (Term I3)}

1. The admitting psychiatrist informs the National/local Council of Mental Health: NCMH with a report justifying the reasons involuntary admission, with comment on mental capacity of the patient within 24 hours.

2. The National/local Council of Mental Health: NCMH, responsible for delegating an independent psychiatrist to evaluate the patient regarding the accuracy of the criteria of the involuntary admission within 3-7 days.

3. The patient has the right to complain about the involuntary admission to the NCMH.

\section{Problems of schizophrenia}

I. Cognition: Lack of logical consistency, playfulness with logic, thought processes are strange no conclusions based on reality or logic despite of high intelligent.

II. Language and speech: Concrete attitude, obscure, private symbols, paleo-symptoms, loosing of associations, Oddities. Symbols with meanings within expressed, abstracting reasoning, residual thoughts, Poverty of speech and reduction of speech content.

III. Volition: Apathy feeling, drained of energy of interest of normal goals and unable to start or follow through on a course of action. ${ }^{11}$

IV. Affect: Inappropriate affect and emotion Affect logic, ${ }^{12}$ and its relations to schizophrenia. Ambivalence, incoherence and affective flattening (the type of emotional dysfunction emotion Vs. the specific forms and content of though).

V. Insight: Lack of insight: most prevalent symptom contributes to unwilling to accept treatment.

VI. Stigma: Has acted a powerful toxic agent thwarting the healing of the human spirits and wounds of the disorder. ${ }^{13}$

\section{The Study}

I. Patient's capacity is determined nearly by clinician's judgments based on patient's symptoms and available information.

II. It is a common concept that psychiatric patients are generally incompetent of making treatment decision and lack of capacity are associated with clinical and legal variables such as psychiatric illness, illness severity and involuntary admission.

III. Among most of our clinical constructs, insight is the strongest discriminator of competency, yet abstracting the mental capacity to the insight is not coinciding with the view of Egyptian law.

IV. After legalization of the Egyptian Law of the Care of the Mentally Ill Patient, this is the first effort to measure competence of making treatment decision in Egypt with the use of standard and objective assessment tools.

V. The current study is aiming make a manuscript for the application of the new Egyptian law by objective assessment of the competence, symptoms severity affecting deteriorating in functions in schizophrenic patients, versus subjective interpretation of the law.

VI. A primary step in a more wide scale project for objective assessment of competence in other types of mentally ill patients.

VII. The study is performed as an audit for the performance of the psychiatrists in admission of schizophrenic patients according to their understanding of the law and clinical abilities to evaluate patient's volition and mental capacity (competence): Assessment tools versus subjective way.

\section{Aim of the work}

I. To define a methodology for the application of the terms stated by the relatively new law as regard the (volition and competence).

II. More understanding of the application of the law for mentally ill patients through objective assessment of competence to consent to treatment using forensic instruments and clinical scales.

III. Demonstrate how objective assessment may evaluate and enhance the decision making capacity.

\section{Materials (Schizophrenic Inpatients)}

\section{Inclusion criteria: no detained patients.}

I. Ethical acceptance: for the patient best interest, no risk and applying the Egyptian Law.

II. Three cases ( $\mathrm{Z}, \mathrm{S}$ and $\mathrm{H})$ as samples of common questions in dealing with schizophrenic patients regarding competence assessment. Written consent, if any, does not mean competency.

i. Z: 36 years old, single male, chronic schizophrenic previously admitted to mental hospitals 7 times before. 
a. Came with his family.

b. Admitted voluntarily depending on his acceptance (he assumed to ask for discharge after 3 days), with a written consent.

c. The symptoms were not significant for involuntary admission.

d. Had no acknowledgement of his illness.

ii. S: 26 years old, single male.

a. Brought from home by the hospital staff, with no resistance or objection.

b. He asked for voluntary admission.

c. Admitted involuntary (sever symptoms and impending deterioration).

d. Had no acknowledgement of his illness.

iii. H: The patient is 21 pears old, single male.

a. Chronic schizophrenic with exacerbation of illness.

b. Refused to have information and also, the assessment,

c. He told the psychiatrist that he would stay for 10 days, asked for voluntary admission.

d. Admitted involuntarily (severity of symptoms and impending deterioration),

e. Had some acknowledgement of his illness.

\section{Methodology}

Brief Psychiatric Rating Scale (BPRS): appropriate for the evaluating baseline psychopathology, clinical outcome and mental response. 18 -symptoms construct each to be related on a 7-point scale of severity (Table 1).

Z:

I. On admission (voluntary with his family), there were no apparent symptoms denote sever symptoms or impending deterioration that indicates involuntary admission.

II. Scores in BBRS (severity of symptoms and deterioration of functions), coincide with his history as a chronic schizophrenic patient and not indicate involuntary admission.

S:

I. On admission, by a medical team (involuntary), though with

\section{HCR 20:}

no resistance nor medication because of sever deterioration of symptoms: abnormal though content and hallucinatory behavior and disorganization indicate marked deterioration.

II. Severity of symptoms and deterioration of functions indicate involuntary admission.

H:

I. Admitted upon his request (voluntary), though had very severe symptoms (loss of association, incoherence, delusion of control and auditory hallucination, lack of abstract ability and disorganized speech).

II. Severity of symptoms and deterioration of functions (alone) indicate involuntary admission (but assessment of his Mental Capacity was taken in consideration and not only his request).

Table I BPRS.

\begin{tabular}{lllll}
\hline S. No & Item & Z. & S. & H. \\
\hline 1 & Somatic concern & 1 & 3 & 6 \\
2 & Anxiety & 2 & 2 & 6 \\
3 & Emotional withdrawal & 5 & 2 & 4 \\
4 & Conceptual disorganization & 3 & 7 & 7 \\
5 & Guilt Feeling & 1 & 1 & 5 \\
6 & Tension & 4 & 3 & 6 \\
7 & Mannerisms - Posturing & 2 & 3 & 7 \\
8 & Grandiosity & 2 & 4 & 5 \\
9 & Dep. Mood & 4 & 1 & 5 \\
10 & Hostility & 1 & 1 & 2 \\
11 & Suspiciousness & 3 & 4 & 4 \\
12 & Hallucinatory behavior & 5 & 7 & 6 \\
13 & Motor retardation & 1 & 2 & 3 \\
14 & Uncooperativeness & 3 & 1 & 1 \\
15 & Unusual thought content & 3 & 7 & 5 \\
16 & Blunted affect & 4 & 1 & 3 \\
17 & Excitement & 2 & 1 & 3 \\
18 & Disoriented & 1 & 1 & 1 \\
& Total Score & 47 & 51 & 79 \\
\hline & & & &
\end{tabular}

\begin{tabular}{|c|c|c|c|c|c|c|c|c|}
\hline Etremely Sever & Sever & Moderately sever & Moderate & Mild & Very mild & Not & present & Not assessed \\
\hline 7 & 6 & 5 & 4 & 3 & 2 & I & & 0 \\
\hline
\end{tabular}

Global assessment of functioning scales (GAF): Measures global functional level of psychiatric patients. Consider psychological, social and occupational functioning on a hypothetical continuum of mental health illness (Figure 1).

\section{Risk assessment HCR 20} 2).

10 Historical, 5 clinical and 5 risk management variables (Table

\section{The MacCAT-T interview}

Coincides with the essence of mature volition ${ }^{14}$ as regard the ability to evaluate alternatives-choice of one-planning of it-the well to carry it-inhibition of the non welled. 20-25 minutes. Each response: $(2,1,0)$ (Table $3 \&$ Table 4).

Citation: Elghazali AM, Dobie A, Kader MA. Objective forensic assessment of competence versus severity of symptoms and assessment of functioning for schizophrenic inpatients based on Egyptian law. Forensic Res Criminol Int J. 2015; ( I):9-I6. DOI: 10.15406/frcii.2015.0I.00004 


\section{1-100 Superior function \\ 81--90 Minimal symptoms \\ 71--80 Transient symptoms \\ 61--70 Mild symptoms \\ 51-60 Moderate symptoms \\ 41-50 Serious symptoms \\ 31--40 Some impairment \\ 21--30 Serious impairment \\ 11-20 Some danger \\ 0-10 Persistent danger}

\section{NOTE : Use intermediate codes when appropriable eg.45.65.72}

Figure I: GAF.

\section{Z:}

\section{The GAF score is (34):}

Major impairment in several areas: work, family relations and judgment.

S:

\section{THE GAF score (2I):}

a. Behavior is markedly influenced by delusions and hallucinations.

b. Serious impairment in communication and judgment.

c. Inability to function in almost all areas (eg. Educational or social activity).

\section{H:}

The GAF score (40):

Some impairment in reality testing and communication (eg. Speech is illogic, obscure and irrelevant)

Table 2 HCR 20 (using the first version; 1995).

\begin{tabular}{lllcc}
\hline & Item & Z. & S. & H. \\
\hline Historical (Past) & Previous Violence & 0 & 2 & 2 \\
& Young Age at First Violent Incident & 1 & I & 0 \\
Relationship Instability & 2 & 2 & 2 \\
& Employment Problems & 2 & 2 & 1 \\
& Substance Use Problems & 2 & I & 0 \\
Major Mental Illness & 2 & 2 & 2 \\
& Psychopath & 1 & I & 0 \\
Early Maladjustment & 1 & 2 & 2 \\
\hline
\end{tabular}


Table Continued

\begin{tabular}{|c|c|c|c|c|}
\hline & Item & $\mathbf{Z}$. & S. & H. \\
\hline & Personality Disorder & I & I & I \\
\hline & Prior Supervision Failure & 2 & I & 0 \\
\hline \multirow[t]{5}{*}{ Clinical (Present) } & Lack of Insight & 2 & I & 0 \\
\hline & Negative Attitudes & I & 0 & 0 \\
\hline & Active Symptoms of Major Mental Illness & I & 2 & I \\
\hline & Impulsivity & I & I & 0 \\
\hline & Unresponsive to Treatment & I & I & I \\
\hline \multirow[t]{6}{*}{ Risk Mangment (Futur) } & Plans Lack Feasibility & I & I & 0 \\
\hline & Exposure To Destabilizes & I & I & 2 \\
\hline & Lack Of Personal Support & 0 & I & 0 \\
\hline & Noncompliance With Remediation Attempts & I & I & 0 \\
\hline & Stress & I & I & 2 \\
\hline & Total & 24 & 25 & 15 \\
\hline
\end{tabular}

a. The items are; 10 historical factors, concern with the past, 5 clinical items reflect current, dynamic correlates of violence. The future is recognized in 5 risk management items, focus attention on situational post-assessment factors that may aggravate risk.

b. Assessment data was gathered from multiple sources, patient files and observation and consulting colleagues. All information was obtained and every score was rated independently. The items in HCR 20 are scored as

\begin{tabular}{lll}
\hline Weak & Moderate & High \\
$(0-19)$ & $(20-29)$ & $(30-40)$
\end{tabular}

Z:

a. Moderate: (mostly because of his personality: past history and severity of mental illness).

b. Clinical picture at moment is not risky.

c. Admitted voluntarily, though, he had lack of insight.

d. The family experience of the early signs of relapse, helped them to anticipate the exacerbation of the psychotic episode, let him admitted before sever deterioration considering that refusing treatment at home.

S:

a. Moderate severe mental illness, previous violence and early maladjustment.

b. High risk regarding the future, mostly disabilities.

H:

a. Mild, previous violence related to early maladjustment.

b. No lack of insight (may explain his well to be admitted voluntary).

c. High risk regarding future, mostly disability and stress. 
Table 3 MacCAT-T

\begin{tabular}{|c|c|c|c|c|}
\hline & & H. & S. & $\mathbf{Z}$. \\
\hline \multirow[t]{4}{*}{ Erstanding Summary Rating } & Disorder & 0 & I & 2 \\
\hline & Treatment & $\mathrm{I}$ & $\mathrm{I}$ & 2 \\
\hline & Benefits - Risks & $\mathrm{I}$ & $\mathrm{I}$ & $\mathrm{I}$ \\
\hline & Total & 2 & 3 & 5 \\
\hline \multirow[t]{3}{*}{ Appreciation Summary Rating } & Disorder & 0 & $\mathrm{I}$ & 2 \\
\hline & Treatment & 0 & $\mathrm{I}$ & $\mathrm{I}$ \\
\hline & Total & 0 & 2 & 3 \\
\hline \multirow[t]{4}{*}{ Reasoning Summary Rating } & Consequential Thinking & I & $\mathrm{I}$ & 2 \\
\hline & Comparative Thinking & $\mathrm{I}$ & $\mathrm{I}$ & I \\
\hline & Generate Consequences & 0 & $\mathrm{I}$ & 2 \\
\hline & Logic Consistency & 0 & I & I \\
\hline Total & & 2 & 4 & 6 \\
\hline Express Choice (Decision Making ) & & I & 1 & 2 \\
\hline
\end{tabular}

Table 4 Summary.

\begin{tabular}{|c|c|c|c|c|c|c|c|c|}
\hline & \multirow[t]{2}{*}{$\begin{array}{l}\text { Type of } \\
\text { admission }\end{array}$} & \multicolumn{3}{|c|}{ Psychopathology } & \multicolumn{4}{|l|}{ Competence } \\
\hline & & Severity & Risk & $\begin{array}{l}\text { Imminent } \\
\text { Deterioration }\end{array}$ & Understanding & Appreciation & Reasoning & Decision \\
\hline Z. & Vol. & $\begin{array}{l}\text { Moderate } \\
+++\end{array}$ & $\begin{array}{l}\text { Moderate } \\
+++\end{array}$ & High +++++ & Partial +++ & No + & Weak ++ & $\begin{array}{l}\text { Questionable } \\
+++\end{array}$ \\
\hline S. & Invol. & $\begin{array}{l}\text { High } \\
+++++\end{array}$ & $\begin{array}{l}\text { Moderate } \\
++++\end{array}$ & High ++++++ & Partial ++++ & $\begin{array}{l}\text { For Some What } \\
+++\end{array}$ & Average +++ & $\begin{array}{l}\text { Questionable } \\
++\end{array}$ \\
\hline $\mathrm{H}$. & Vol. & $\begin{array}{l}\text { High } \\
++++++\end{array}$ & Low + & High ++++++ & Partial ++ & Clear +++++ & $\begin{array}{l}\text { Strong } \\
+++++\end{array}$ & $\begin{array}{l}\text { Competent } \\
+++++\end{array}$ \\
\hline
\end{tabular}

\section{A-Understanding for:}
a. Disorder
b. Treatment
c. Benefits and risks (summary rating range=0-6).

\section{B-Appreciation for:}

a. Disorder

b. Treatment (summary rating range $=0-4$ ).

\section{C-Reasoning (Thinking Rational About Treatment: TRAT):}

a. Consequential thinking

b. Comparative thinking c. Generating Consequences

d. Logical Consistency (summary rating range $=0-8$ ).

\section{Results and discussion}

Z:

I. Understanding and Appreciation: understood his own explanation of information (Playfulness with logic).

II. Accepted admission responding to family pressure and seeking to be discharged according to his desire reflecting low Consequential thinking and Comparative thinking scores.

III. Generating Consequences and Logical consistency: believes that admission makes no differences for his condition and Denial of illness though accepting medication (Stigma).

IV. Though his insist to be discharged soon, after more information 
and negotiation, he accepted to continue10-14 days therapeutic deal $=$ therapeutic deal

\section{S:}

I. Understanding: The patient accepted the fact that he is ill with had no objections to be admitted regardless how, appreciated the benefits of treatment and admission.

II. Appreciated the benefits of admission and treatment.

III. Choice: A problem in interpreting his well into action; Volition = overt action is recorded + related to conscious decision + definite choice. ${ }^{15}$

IV. Consequential thinking: Asked for voluntary admission.

V. Comparative Thinking: obey the psychiatrist decision as involuntary (the doctor knows better than me).

VI. Generating Consequences: though was brought from home, no resistance.

VII. Logical Consistency: accept the concept of illness and the rule of hospitalization in recovery and rehab.

H:

I. Understanding: had acknowledgement to his disorder.

II. Treatment: was motivated to be treated as inpatient, he agreed with his family about that.

III. No well to receive information about the law. Said, it might confuse him.

IV. Appreciation of disorder: knew that he had a psychotic exacerbation.

V. Appreciation of treatment: had his own predetermined treatment plan.

VI. Reasoning: Comparative thinking: had a reason to be admitted regarding his current condition, eliminating any other alternative (to be treated at home).

VII. Generating Consequences: respected the therapeutic hospital rule in rapid improvement

VIII.Logic Consistency: affected by rigid attitude (10 days enough for me, nonnegotiable!).

IX. Competent: for voluntary admission (free choice) acknowledgement of illness, regardless he lacking information about the law.

\section{Conclusion}

The practical application of the MacCAT-T had faced some problems and also found some solutions:

\section{Understanding:}

a. Problem; difficulty of law terms and concepts, the patient lacks and misunderstands information (hidden goals) and a part of psychopathology (perception/information processing)

b. Solution: to give clear and simple information. Use story, illustrations and cartoon cards.

\section{Appreciation:}

a. Problem: difficult to explain values. Psychopathology (regressed language, concrete attitude)

b. Solution: repeated explanation, summarizing and clarification.

\section{Reasoning:}

a. Problem: subjective or related to the disease. Psychopathology: e.g. loosening of associations- abstract reasoning.

b. Solution: task oriented and clear defined aim.

\section{Decision making:}

a. Problem: not interested- lack of motivation-lack of free wellnegative acceptance-lack of volition to decide or express a choice. Psychopathology: - conflicting feelings-Affect Logic.

b. Solution: enhancement of decision making ability - negotiating competence "the turning point from resistance to cooperation and alliance: push and pull stage" 16 adopting integrated view of psychiatry and law and free the patient well "Volition is the ability to breakthrough static scripts". ${ }^{15}$

Severity of symptoms doesn't necessarily means to be multiple or high score, one specific symptom might be a good indicator for impending danger (BPRS). The degree of the impact of symptoms upon the cognitive functions doesn't mean there would be impending deterioration. Yet, the impending deterioration is significantly related to the severity and activity of psychotic symptoms if not treated (GAF). HCR20, is of great value upon the decision of admission and treatment and more important as regard the decision of discharge. Though, it has low predictability, yet it indicates the present dangerous well. The MacCAT-T gave a chance for negotiating competence and enhancement of mental capacity.

\section{Acknowledgments}

None.

\section{Conflicts of interest}

The author declares that there are no conflicts of interest.

\section{References}

1. Beauchamp T, Childress J. Principles of Biomedical Ethics, $5^{\text {th }}$ edition. Oxford University Press. 2001

2. Thomas Grisso, Randy Borum, John F Edens, et al. Evaluating competencies: Forensic assessments and instruments, $2^{\text {nd }}$ edition. Boston Springer Science, Business media. 2005;391-394, 398-405, 421-425.

3. Helmchen H, Sartorius N. Ethics in psychiatry Europian contribution, $1^{\text {st }}$ edition. International library of ethics and new medicine. 2010;133.

4. Helmchen H. Research with patients incompetent to give informed consent. Current Opinion in Psychiatry. 1998;11(3):295-297.

5. Markson LJ, Kern DC, Annas GJ, et al. Physician assessment of patient competence. J Am Geriatr Soc. 1994;42(10):1074-1080.

6. Marson DC, McInturff B, Hawkins L, et al. Consistency of physician judgments of capacity to consent in mild Alzheimer's disease. $\mathrm{J} \mathrm{Am}$ Geriatr Soc. 1997;45(4):453-457. 
7. Vollmann J, Bauer A, Danker-Hopfe H, et al. Competence of mentally ill patients: a comparative empirical study. Psychol Med. 2003;33(8):1463-1471.

8. Jeste DV, Depp CA, Palmer BW. Magnitude of Impairment in decisiona capacity in people with schizophrenia compared to normal subjects: an overview. Schizophr Bull. 2006;32(1):121-128.

9. John E Overall, Donald R Gorham. The brief psychiatric rating scale. Psychological Reports. 1962;10:799-812.

10. Diagnostic and Statistical Manual of Mental Disorders, $4^{\text {th }}$ edition. Axis V.

11. Ronald J Comer. Abnormal Psychology, $7^{\text {th }}$ edition. Worth Publishers 2010;1-619.
12. Ciompi L. Affect logic: an Integrative model in psyche and its relations to schizophrenia. Br J Psychiatry Suppl. 1994;23:51-55.

13. Sartorius N, May N. Schizophrenia, $2^{\text {nd }}$ edition. University of Napoli, Italy. 2002.

14. Areti Silvano. Interpretation of Schizophrenia, $2^{\text {nd }}$ edition. Crosby Lockwood Staples, UK. 1974;756.

15. El-Rakhawy Y. Portrait of the Psychiatric Patient "Special Reference to Egyptian \& Arab Culture". EPA Publications. 1994.

16. Dobea A, Bahaey W, AbdelKader M. Impact of Insight Enhancement Program on Short Term Outcome of Schizophrenic Patients. Approved for submission in xiii. World Congress of Psychiatry. 2005. 